\title{
ANÁLISIS DE LAS NARRATIVAS DE SUJETOS TRAUMATIZADOS POR ABUSO
}

\section{Analysis of trauma narratives reported by abused individuals}

\author{
Antonio Sánchez Antillón* - Instituto Tecnológico y de Estudios Superiores de \\ Occidente - ITESO, Universidad Jesuita de Guadalajara \\ Osvaldo Gutierrez Castañeda** - Universidad de Cetys, Tijuana - México \\ Luis Fernando Macías García*** - Universidad de Guanajuato, México
}

\section{Resumen}

El objetivo de la investigación es la vivencia traumática por abuso moral y sexual en la infancia y sus estragos actuales. Se analizan los relatos de vida de cuatro sujetos adultos (un hombre y tres mujeres) de edad entre 36 y 60 años. La investigación es de corte cualitativo y el método de análisis se basa en la teoría del relato. Las narraciones coinciden en: abuso moral o sexual; huida del núcleo familiar; repetición de abuso y padecimiento actual por revivencia. $Y$, en el caso específico de las mujeres, hay intentos o ideación de acabar con la propia vida. Se concluye que el trauma y la desestimación es sino de lo que se ilustra bajo la categoría del "no lugar existencial".

Palabras claves: Trauma, abuso moral, abuso sexual, teoría narrativa.

\begin{abstract}
The subject of the research is the traumatic ordeal caused by moral and sexual abuse during childhood, and its long-term consequences. Life stories of four adult individuals (one man and three women) between 36 and 60 years old were analyzed. The research is qualitative and the method of analysis is based on the Narrative Identity Theory. The stories have some coincident points: moral or sexual abuse; escape from their family nucleus; repetitive abuse, and current affliction due to relived experience. In the specific case of women, there are reports of suicide ideation and attempts. . It is concluded that the trauma and the rejection are consistent with the construction of an "existential no-place".
\end{abstract}

Keywords: Trauma, moral abuse, narrative theory.

\footnotetext{
*Psicólogo. antonios@iteso.mx ORCID: https://orcid.org/0000-0002-5763-4245

** Psicólogo.psic.gtz78@gmail.com ORCID: https://orcid.org/0000-0003-1434-7390

*** Sociólogo. luisfer56@gmail.com ORCID: https://orcid.org/0000-0001-7416-2369
} 


\section{PRESENTACIÓN DEL PROBLEMA}

Desde las obras de la Grecia clásica con Aristóteles sabemos que el sentir se destaca como un criterio diferenciador entre lo animado y lo inanimado y de frente al Ser (ousía) que se despliega como naturaleza (físis). El sentir puede estar expresado en la naturaleza en diferentes formas: la vida vegetativa, animal y la que subsume las otras dos con el atributo diferencial de lo intelectivo: en el humano. El sentir en tanto humano, tiene como principio base la discriminación de los estímulos internos y externos, cualificados por la diferencia entre el placer y el dolor. La búsqueda misma del bien no es para este clásico sino la experiencia y los hábitos que pueden llevar a una buena vida o al padecimiento por los efectos propios de los vicios. Supone que el incesto o el nacer con un daño físico son impedimentos para que el sujeto pueda regirse por la virtud.

Aristóteles (1999) discurre que tener una buena vida requiere ciertas condiciones: un tiempo, no envejecer demasiado rápido o lento; cuidar del cuerpo y tener buena fortuna (el azar). Reconoce que el esfuerzo implica cierto desgaste, cierto dolor primario propio del existir, pero ya establecido el hábito se vuelve placentero. Expone que las actividades de recreación, descanso, sueño y el tener aspiraciones deseosas tienen como fin el goce de la vida. Aunque también reconoce que hay ciertos estados que interrumpen o dificultan la buena vida, a saber: daño por nacimiento o el padecimiento por ser víctima de la lujuria de otros, por lo que el sujeto queda en estado morboso.

Por su parte Nietzsche (1997), supone que la pregunta por el sufrimiento se dio en el momento en que la inteligencia despertó y quedaron suspendidos los instintos, por lo que tuvo que hacerse cargo de su propio existir. De acuerdo con esta tradición occidental de pensamiento, Freud (1930/1986) señala que la amenaza del sufrimiento aparece desde tres fuentes: desde el cuerpo, que parece condenado a la declinación y la muerte; del lado del mundo exterior, ya que muchos de nuestros padecimientos provienen de fuerzas destructoras que no podemos controlar; $y$, por último, de los vínculos con los demás. Sugiere entonces que la manera en que uno conoce el sufrimiento solo es a partir de la experiencia, teniendo como continente el cuerpo, la naturaleza y la sociedad. La frustración del principio del placer por el de la realidad social es la variable que posibilita el desarrollo autoplástico como aloplástico en su relación del individuo con su medio. En sus escritos sociales, Freud (1930/1986) señala que la civilización no puede ser sino a condición de una serie de frustraciones o represiones sistemáticas de los deseos humanos; a la par de la obtención de una serie de satisfacciones sustitutivas, ideales e ilusiones, que se van acompañadas con decepciones inevitables; de tal manera que estar insertos en la civilización nos empuja a sufrir de una serie de ilusiones y malestares.

Bajo estos mismos principios Levi-Strauss, en la introducción a la obra de Mauss (1979) recuerda que la cultura es un sistema de símbolos, situados en el lenguaje, así como las reglas de unión matrimonial, las relaciones económicas, el arte, la ciencia y las pautas religiosas. Así mismo, los fenómenos percibidos como trastornos mentales no escapan a este modo de valoración, por lo que cada sociedad describe lo normal de acuerdo a cierto orden colectivo esperado.

Freud (1893-95/1985) innova cuando de acuerdo a la terminología de su tiempo habla acerca de la neurosis traumática, la cual la sitúa entre un proceso ocasional y un fenómeno patológico. Encuentra ciertas coordenadas alrededor del fenómeno traumático, un decir simbólico y la vivencia que se desborda por displacer; el afecto de horror será la causa eficiente que lo sostendrá. Propone que hay ciertas vivencias que son traumáticas porque rompen el principio de homeostasis, sea por la fuerza de impacto o por su repetición, sumatoria de eventos. Las reacciones frente a un fenómeno adverso puede ser la defensa corporal o verbal, la huida o el atrapamiento, quedar paralizado. Infiere que el recuerdo de la vivencia por el displacer que provoca quiere ser olvidado, reprimido. Cuando falla la represión y además no hay tramitación del evento este aparecerá desfigurado, haciendo síntomas. El afecto de angustia o terror vivenciados en el evento traumático puede emerger ligado a otras representaciones o desplazado en otros contextos (Freud, 1923/1984; 1940/1986). El efecto traumático negativo es un esfuerzo inconsciente por tratar de evitar a toda costa que se recuerde o repita (Freud, 1939/1986). El sujeto se defenderá previendo, evitando o inhibiendo el acto o desplazando y desfigurando el contenido mediante reacciones fóbicas. Los efectos 
positivos del trauma se dan por fijación al fenómeno adverso, por lo que se esfuerza en mantener vigente el trauma recordando o repitiendo. Cuando la vivencia traumática sexual o agresiva se da en las etapas tempranas emergerá con posterioridad en vínculos análogos. Freud (1939/1986) ofrece una metáfora poderosa cuando refiere que la vivencia traumática infantil provoca una sangría energética de modo que en el proceso de desarrollo el sujeto tendrá que invertir una gran cantidad por tratar de reparar ese daño. La desmezcla pulsional del evento traumático deja una cantidad de energía libre que lleva al sujeto a acciones autodestructivas (1923/1984; 1940/1986).

La descripción de Freud sobre este fenómeno es consistente con investigaciones recientes, en donde se precisa una diversidad de consecuencias en infantes que han sufrido abuso sexual, el cual lo entienden como evento traumático. Rind, Bauserman \& Tromovich (1998, en Malón, 2008) informan la aparición de ciertos trastornos asociados con la experiencia de abuso sexual en la infancia temprana:

Problemas de alcohol. Ansiedad. Depresión. Disociación. Trastornos de alimentación. Hostilidad. Problemas en la relación con los otros. Pérdida del locus de control. Síntomas obsesivocompulsivos. Paranoia. Fobias. Síntomas psicóticos. Problemas de autoestima. Problemas de ajuste sexual y social. Somatización. Pensamientos y conductas suicidas. Malestar general (Rind, Bauserman \& Tromovich, 1998, en Malón, 2008, p. 178).

Haileye (2013) reporta también que, en una población de Etiopía, mujeres que habían sufrido de abuso sexual en la infancia eran más propensas a desarrollar depresión, ansiedad, pánico y trastorno de estrés postraumático. De la misma manera, el estudio llevado a cabo por Norman, Byambaa, De, Butchart, Scott, \& Vos (2012) arrojó que existía una mayor propensión a desarrollar un trastorno depresivo en personas que habían sufrido algún tipo de abuso durante la infancia. Además, algunos participantes con vivencia de abuso, que no habían recibido un diagnóstico psiquiátrico mostraban ansiedad, sentimientos de culpa y problemas de sueño (Yüce, Karabekirglu, Yildrim, Sahin, Sapmaz, Babadag,
Turla, \& Aydin, 2015). Por su parte, Rani \& Kumar (2016) en un estudio llevado a cabo en India mostró que las mujeres abusadas mostraban ansiedad y depresión, además de elevados niveles de estrés. En un grado menor, encontraron relación entre los niveles de estrés e ideaciones suicidas. Amado, Arce \& Herraiz (2015) encontraron además distimia en estos sujetos. En los pacientes con trastornos psiquiátricos que habían referido abuso sexual infantil, Pereda (2010) encuentra como consecuencia grave la revictimización, que consiste en "la experiencia posterior de violencia física y/o sexual en víctimas de abuso sexual infantil por agresores distintos al causante del abuso en la infancia" (Maker, Kemmelmeier \& Peterson, 2001 en Pereda, 2010).

Villanueva (2013) encuentra que "los síntomas más frecuentes del trauma son: vueltas al pasado, sueños con representación del suceso ocurrido, insomnio y depresión; síntomas que suelen persistir durante mucho tiempo, años, y a veces, durante toda la vida (p. 461), además de una sexualización de las relaciones interpersonales.

Rus \& Buzarna (2013) nos dicen que los síntomas psicológicos son la evidencia de que ha habido un trauma mental. Encuentran síntomas directos en el infante: vómitos, anorexia, pesadillas, desinterés, dificultades escolares, entre otros. Además de que generan estrategias de afrontamiento útiles en la infancia, sin embargo, "en la adultez, puede obstaculizar al superviviente el tomar su propia vida en sus manos" (p. 504). Durante la adolescencia, las víctimas presentan pensamientos suicidas: "así, el suicidio puede ser visto como la única salida del dilema: decir, o no decir" (p. 506). Y es que parece ser que "el decir" tiene una importancia fundamental en el curso que se seguirá luego del evento traumático. Santana \& Machín (2005) enuncian consecuencias del abuso como: "Fantasías de complicidad, con sus consecuencias en la identificación y elección de objeto sexual. El desdibujamiento de los roles parentales. La transmisión imaginaria y simbólica e y la expectativa de abuso transmitida a su descendencia” (p. 691).

La investigación de Sigurdardottir, Halldorsdottir \& Bender (2012) arrojó resultados similares a los ya anotados respecto de las víctimas de violencia 
(presentaban trastornos de ansiedad, depresión, sentimientos de culpa, workaholism, además de que encontraron cierta tendencia a que ciertos sujetos fueran padres sobreprotectores, o con miedo a tener contacto físico con sus hijos) Ssin embargo, anotan: "The men have lived in repressed silence and along with the feelings of worthlessness have come close to taking their own lives" (p. 691). Además, especifican que: "In experiencing the trauma, the men experienced deep suffering characterized by intense fear, emotional disconnection, self-blame, guilt and shame (...) they lived in repressed silence, which became the tragic story of their lives" (p. 691).

Villanueva (2013) menciona que una experiencia de abuso puede llegar a ser más traumática cuando la persona perpetradora proviene del propio núcleo familiar, pues genera "sentimientos contradictorios en cuanto a la confianza, la protección y el apego que se espera y se siente con relación a los propios familiares" (p. 461). Agrega: "No todos los niños manifiestan el mismo grado de afectación. Para algunos, el abuso puede significar un trauma y para otros las consecuencias pueden ser diferentes" (p. 461).

Al respecto, Boyce \& Harris (2011) dicen: "es claro que no todos los niños abusados tendrán secuelas psicológicas". Siguieron de cerca un estudio llevado a cabo en Australia, donde el $64 \%$ de los participantes (víctimas de abuso sexual) no presentaban secuelas psiquiátricas. Estos autores proponen que la resiliencia de las personas con abuso sexual, depende directamente de si hay o no un ambiente que acompañe el proceso de recuperación (p. 609).

\section{Preguntas de investigación:}

Siguiendo las pesquisas antes presentadas, lo que acá se plantea dilucidar es:

- ¿A raíz de que eventos de sus vivencias los entrevistados atribuyen que su vida se convirtió en padecimiento?

- ¿Qué relaciones expresan entre el padecimiento actual que los llevó a la atención psiquiátrica y sus vivencias anteriores?

- ¿Cuál es la posición y relación de la voz narradora con los personajes que aparecen en sus relatos?

\section{Objetivo de investigación:}

Describir y analizar las narrativas de cuatro pacientes que han sido atendidos en consulta externa con medicamentos psiquiátricos en miras de comprender el campo de sentido que estas personas declaran en sus relatos como causales de su sufrimiento.

\section{METODOLOGÍA}

\section{Tipo de Investigación:}

Esta investigación es cualitativa en tanto que se busca comprender el campo de significados que los sujetos atribuyen a sus vivencias, así como su posición subjetiva.

\section{Método:}

El método de análisis está basado en la teoría estructural del relato.

Esta teoría reconoce que toda escritura tiene una serie de redundancias que permite que se puedan sugerir ciertos perfiles narrativos. Así sucede en los distintos estudios hechos en el campo de la literatura, por ejemplo, pueden evidenciar la estructura del cuento, la novela etc. Y dentro de estos estilos literarios se pueden encontrar la peculiaridad propia de cada autor; cada cual cuenta a su manera. Ya desde los años setenta del siglo XX, cuando se transfirió el uso de la hermenéutica y la semiótica a otros saberes como la sociología y la psicología, se enriquecieron las disciplinas. El hablante de la vida cotidiana se caracteriza también por expresarse bajo ciertas recurrencias o estilos. La psicología y el psicoanálisis ha podido evidenciar sus conceptos de histeria y obsesión bajo ciertas retóricas particulares. Liberman (1982) y White (citado por Ramos, 2001) articularon la retórica y la poética con la práctica psicoterapéutica e investigación. Liberman fertilizó con ese saber el campo psicoanalítico y White la psicología narrativa. Maldavsky (2004; 2013), siguiendo a su maestro Liberman articulará el saber psicoanalítico con la semiología y propone ciertas secuencias narrativas que articula con la teoría freudiana de las erogeneidades. Ambos autores además tienen como referentes las propuestas de la lingüística francesa de finales del siglo XX. 
De acuerdo con las pautas propuestas por la teoría estructural del relato de Greimas, Bremond, Todorov y Barthes (1970) asumimos que el relato es una concatenación de frases que, dada su secuencialidad lógica genera un sentido mayor. El relato como expresión discursiva se analiza a partir de cierta textualidad la cual se organiza bajo cierta temática y temporalidad lógica o cronológica. Toda historia está constituida por una serie de escenas las cuales pueden describir los caracteres de los personajes o situaciones; integrar el sentido entre ellas; sostener el suspenso narrativo dando indicios y apuntalar el nodo o conclusión.

Algunos autores se fijan más en sus análisis que en el nivel de las acciones (Todorov, 1970) y otros en la sintaxis de los relatos (Bremond, 1970) o en los caracteres de los actantes o personajes y las posiciones paradigmáticas (Greimas, 1970). Adam (1985) articulando algunas de estas premisas, sugiere una secuencia prototípica que va del anuncio del tema, el estado inicial del relato, el elemento que complica ese estado, una reacción o evaluación de éste, una primera resolución a esa complicación y una situación final, y como prólogo la emergencia de una moraleja o evaluación de la secuencia. En esta lógica articula a la vez, el tiempo, la temática, un actante, los predicados atribuidos, el proceso de transformación de las acciones y los caracteres y la evidencia entre las relaciones causales de los actos. Maldavsky (2004) siguiendo a Adam, asume que la secuencia prototípica de los relatos incluye cinco momentos: estado inicial, despertar del deseo, intento de consumación, consecuencia del intento y estado final. En el presente trabajo asumimos esta propuesta en el momento de sistematizar los relatos de los entrevistadores. Por otro lado, siguiendo a Blanchet (1987), asumimos que, en las entrevistas a diferencia de los textos literarios, el campo de sentido de las narraciones se va construyendo en el diálogo entre entrevistado y entrevistador. Y que el entrevistado suele hacer uso de las narraciones para explicar eventos pasados, dar información o justificar el porqué de sus acciones. Estas distintas recomendaciones se tienen en cuenta en el proceso de fragmentación y acomodo de los resultados.

\section{Participantes:}

Cuatro personas adultas, de 36, 47, 50 y 60 años entrevistadas en consulta externa que reciben medicamentos psiquiátricos.

\section{Previsiones éticas:}

Después de informales a los sujetos sobre los objetivos de la investigación, se les leyó la carta de consentimiento informado en la cual se advierte que la información recabada sería utilizada cuidando en todo momento su anonimato. En la carta se aclara que la información sería utilizada para la producción de documentos académicos y su eventual publicación, por lo que en todos los datos trasmitidos se cuida no dar datos particulares que pudieran permitir la identificación de los entrevistados. En la carta se enuncia el responsable del resguardo de la información. En acto de justicia retributiva se ofreció a los entrevistados, sesiones de escucha terapéutica en caso de requerirla. Se les entregó la carta de consentimiento la cual fue firmada de conformidad por los participantes.

\section{Técnica de recolección y análisis de datos:}

La recolección de la información fue mediante entrevistas semiestructuradas. Esta se realizó a cada sujeto, el tiempo invertido en cada una de ellas fue de una hora. Estas se realizaron en oficinas o salas que la institución dispuso para ello.

Ya con la información grabada se hicieron las transcripciones. El texto se leyó varias veces para comprender el campo de sentido e insistencias narrativas. Después, el material se fragmentó alrededor de las distintas temáticas emergentes en los relatos. Posteriormente se hizo una reconstrucción de éstos para tener una mejor comprensión de la secuencia narrativa y de las acciones de los personajes.

\section{RESULTADOS}

A continuación, se presentan los resultados sistematizados de las entrevistas realizadas. Se inicia con la sinopsis la cual es una descripción sucinta de cada uno de los sujetos. Posteriormente en un cuadro global bajo la secuencia prototípica del relato se sintetizan las consistencias narrativas de los sujetos entrevistados, destacando en las secuencias los eventos y personajes relevantes (Maldavsky, 2004). Después se hace un análisis descriptivo precisando mediante viñetas textuales escenas relevantes expresadas como 
causa primera y eficiente del sufrimiento subjetivo. Al final se discuten los resultados con el concepto de trauma y las investigaciones expuestas en el planteamiento del problema. Finalmente se discute sobre una constante destacada en los relatos, a saber: los adverbios de negación. Estos se piensan desde dos conceptos el sujeto del no y la solicitud negativa, ideas expuestas por filósofos existencialistas.

\section{Sinopsis}

El sujeto uno (S1), narra dos escenas infantiles en las cuales fue abusado sexualmente. La primera vez fue en casa de un vecino él tenía seis años y el vecino 25. La mamá del abusador golpea al agresor públicamente, mientras que los papás y hermanos del abusado sólo se quedaron viendo. El segundo abuso, fue en la primaria cuando tenía ocho años y el agresor 20. Mientras abusaban de él, recuerda las risas de sus compañeros. Al estar cursando el último grado de escuela primaria otro chico trató de abusar de él, esta vez se defendió e hizo sangrar al agresor. A partir de estos hechos, los amigos y hermanos se burlaban de él y le decían joto. A causa de lo cual se peleó mucho en la infancia y hasta la fecha, cuando va por la calle y se lo gritan. Su padre durante su infancia lo maltrataba verbal y físicamente. Decide salir de su casa a los 17 años para ir a trabajar a la ciudad. Tuvo tres amores varones en su vida, dos de los cuales murieron. Cuando era amante del primero, este le pidió que lo dejará y se casara con su prima. Obedeció se casó y terminó su relación con el amante. Actualmente, aunque tiene su familia y trabaja para ella, sufre por todo lo que ha vivido. Dice haber padecido muchas cosas que no puede olvidar y que a eso se suma el mucho trabajo que tiene por lo que le dan súbitos ataques de dolor en el cuerpo, estrés, angustia y tristeza. Ha ido a varias atenciones psicológicas, y cuando vieron que estaba deprimido le sugirieron buscara otra ayuda. Estas fueron las razones que le llevaron a buscar atención psiquiátrica.

El sujeto dos (S2) siendo niña vive maltrato de la madre quien además la deja a cargo de una hermana joven que se intentó suicidar. Ella decide huir de su casa y fue a otra ciudad a buscar a su abuela quien era alcohólica. Después de un tiempo de vivir con ella y padecer maltrato, decide escaparse nuevamente. Tenía doce años cuando decide abandonar a la abuela.
Se fue caminando sin rumbo hacia otra ciudad. Un joven al verla sola por la ruta le ofreció aventón, se la llevó a un motel y la violó. Después la deja en el mismo camino donde la encontró. Otro joven de una gasolinera le ofrece un lugar donde quedarse, éste vivía con su pareja y la estuvieron ayudando por un tiempo. Siendo adolescente se contrató en un burdel en donde servía copas, al llegar a los 18 empezó a trabajar en la prostitución. Un joven de otro estado la conoció en el burdel y le propuso que se fuera a vivir con él. Escapó de la cantina y se fue a vivir con él, un tiempo después se casó con él y tuvo un hijo. La vida con él marido fue difícil porque era alcohólico y no trabajaba. Ella tenía que trabajar y dejar a sus hijos encargados. Después de varios conflictos con él y su suegra decide huir. Se va a vivir a otra ciudad y conoce a otro hombre, uno que trabajaba en las fuerzas de seguridad. Este hombre no sólo no le daba dinero para mantenerse, sino que además la golpeaba. Después de un tiempo lo abandona. Su marido actual sí la trata bien y la sostiene económicamente. Actualmente empezó a sufrir desánimo y desesperanza, pérdida de interés por las cosas. Se ha infligido daño en su cuerpo, ha tomado pastillas para morirse y sigue teniendo ideación de acabar con su vida. Dice que su vida ha sido de sufrimiento: no ha tenido lugar, ni a nadie. Estas fueron las razones que la llevaron a buscar atención psiquiátrica.

El sujeto tres (S3) reconoce que en su vida todo ha sido sufrimiento. Declara que su papá era un violador, que la violó a ella y a todas sus hermanas. Su madre era una persona analfabeta que además no sabía cuidar a sus hijos. Ella sale de su casa dada la situación familiar. Se va a vivir con su primera pareja a los 16 años. Tuvo un hijo con él. Su marido la trataba con insultos y violó a su hijo. Dejó a esta pareja y se casó con otro hombre con quien tuvo otra hija. Esta segunda pareja tuvo varias aventuras con otras mujeres. Ella dice que aguantó todo con tal de mantener la familia unida, y darles eso que ella no tuvo. Cuando se enteró por su hija que su marido la estaba engañando con su sobrina fue que decidió dejarlo. Después lo perdonó y empezó a tener problemas con su cuerpo: se ahogaba y le llegaban angustias inexplicables. Posteriormente se divorcia del marido. En el momento actual de su vida tiene estallidos de rabia y no se quiere levantar de la cama, es por ello que la llevaron al psiquiatra y 
a la psicóloga. Dice sufrir porque le vienen imágenes del maltrato de su primer esposo a su hijo y se culpa de lo que él vivió. Pues atribuye que por ello su hijo sufre actualmente de adicciones. Así mismo le vienen las imágenes de abuso de su padre a ella. Siente que dado lo que ha vivido, ella era fría y no les dio el cariño suficiente a sus hijos. Se culpa, y siente que ya no quiere vivir.

El sujeto cuatro (S4), que sus padres estaban divorciados. Ella y su hermana vivían con su madre y su padre vivía enfrente de su casa con otra esposa. El inicio de su sufrimiento lo atribuye al abuso sexual cuando era niña, por parte de un tío paterno y de un señor al cual le cuidaban una casa. Éste último abusaba tanto de ella como de su hermana. Describe a su madre como alguien que no hablaba y nunca jugaba con las hijas. Después del divorcio de sus padres, las hijas se quedaron solas. Cuando cumplió 15 años se casó para irse de su casa. Lo que encuentra en su matrimonio son maltratos morales y físicos por parte de su pareja. Comenta dos episodios en donde atentó contra su vida, después del primer intento fue internada. Ahora después del segundo está siendo atendida por sus hijas. Expresa que sólo quiere morir, porque está deprimida y recuerda los sufrimientos de su infancia. Ella había soportado vivir porque veía que sus hijas la necesitaban, pero ahora que ya salieron de casa y no la necesitan no quiere vivir.

En la siguiente tabla se muestran las coincidencias en la secuencia narrativa de los tres entrevistados:

Tabla 1.

Secuencia global: consistencia narrativa de los entrevistados.

\begin{tabular}{|c|c|c|c|c|}
\hline Estado Inicial & $\begin{array}{c}\text { Primera } \\
\text { transformación: } \\
\text { despertar del deseo }\end{array}$ & $\begin{array}{l}\text { Segundo: Tentativa } \\
\text { del consumo del } \\
\text { deseo }\end{array}$ & $\begin{array}{c}\text { Consecuencia del } \\
\text { intento }\end{array}$ & Estado final \\
\hline $\begin{array}{l}\text { Una historia infantil que } \\
\text { arranca con la transgresión a } \\
\text { sus cuerpos por un personaje } \\
\text { con el atributo abusador moral } \\
\text { y sexual. En el caso del S1, } \\
\text { los abusadores sexuales son } \\
\text { jóvenes. En el S2, el abusador } \\
\text { aparece como un joven que } \\
\text { ante la salida de su casa le } \\
\text { ofrece darle un aventón. El } \\
\text { S3, el abusador fue su propio } \\
\text { padre. } \\
\text { El S4, fue abusada por un tío } \\
\text { y otro señor que vivía en su } \\
\text { casa. } \\
\text { Además, expresaron que } \\
\text { fueron abusados moralmente } \\
\text { por alguno o ambos padres, } \\
\text { con frases de desestimación y } \\
\text { rechazo sobre su ser o hacer. }\end{array}$ & $\begin{array}{l}\text { En los cuatro } \\
\text { entre vistados } \\
\text { se emprende un } \\
\text { autoexilio, como } \\
\text { una forma de } \\
\text { escapar de los } \\
\text { abusos familiares. } \\
\text { Migran de sus } \\
\text { pueblos a ciudades } \\
\text { grandes. }\end{array}$ & $\begin{array}{l}\text { Los cuatro sujetos } \\
\text { expresan que } \\
\text { buscaban encontrar en } \\
\text { sus parejas la familia } \\
\text { que no tuvieron y } \\
\text { ofrecerle eso a sus } \\
\text { hijos. } \\
\text { Intento de tener una } \\
\text { vida diferente a la } \\
\text { que se tuvo: tener una } \\
\text { familia. } \\
\text { Lo que encuentran } \\
\text { los Sujetos 2, } 3 \text { y } 4 \text { es } \\
\text { otro abusador en las } \\
\text { parejas. } \\
\text { En el caso del S1, sus } \\
\text { amores masculinos } \\
\text { se destacan por } \\
\text { abandonarlo. }\end{array}$ & $\begin{array}{l}\text { Las mujeres (S2, y S3, } \\
\text { S4) viven o vivieron } \\
\text { con hombres que } \\
\text { abusaban moralmente. } \\
\text { Y en el S3 el abuso } \\
\text { sexual se repite en uno } \\
\text { de los hijos. } \\
\text { En el relato del S1, los } \\
\text { abusadores morales son } \\
\text { diversos: aparecen en el } \\
\text { trabajo, en el barrio, la } \\
\text { escuela, la familia. Las } \\
\text { detracciones verbales } \\
\text { son por su apariencia } \\
\text { femenina. }\end{array}$ & $\begin{array}{l}\text { Los tres sujetos buscan atención } \\
\text { psicológica y psiquiátrica porque } \\
\text { padecen súbitos afectos de angustia, } \\
\text { ahogamiento, tristeza, desánimo, } \\
\text { astenia y dolor corporal. } \\
\text { Las mujeres entrevistadas (S2, S3, y } \\
\text { S4) han tenido al menos un intento } \\
\text { de acabar con sus vidas ayudadas de } \\
\text { pastillas. } \\
\text { El final de sus relatos es una } \\
\text { expresión de contrastes respecto a } \\
\text { otras voces que dicen que la vida } \\
\text { es para disfrutarse, que es hermosa. } \\
\text { No entienden por qué se dice eso, ya } \\
\text { que para ellas la vida es dolor. }\end{array}$ \\
\hline
\end{tabular}


En las consistencias narrativas de la tabla 1, se destacan en todas las entrevistadas(os) vivencias de desamparo al inicio de sus vidas, intentos de salir de esas situaciones adversas de maltrato y humillación, con consecuencias disfóricas. Según sus narrativas el intento de salir de la situación de abuso y maltrato por parte de alguno de los padres fracasan en tanto que se repiten las mismas escenas con atacantes semejantes o se agrava la situación, como en el caso de S2 y S3 quienes vuelven a encontrar abusadores sexuales. Así pues, la consecuencia del intento de consumar su deseo al final de la secuencia también aparece disfórica, fracasada y con una característica muy peculiar, a saber: el conflicto relacional de abuso emerge sintomáticamente en el cuerpo como una desconcertante angustia automática, dolor o astenia. El S1 refiere: "Siento dolor en la espalda, comienzo a vomitar, es cuando es señal de que estoy hasta la madre de estrés y depresión". El S1, además expresa que sus síntomas tienen un antecedente: "[...] yo pienso que todo lo que he pasado de chiquito, todavía no sale. Ahorita pues lo que me explicó el psiquiatra, de ahí viene, ahí está... no le he podido sacar... cerrar el ciclo totalmente, porque fueron muchas cosas en mi vida". El S2, relata "[...] no tenía ganas de hacer nada, más que estar acostada, no hablar con nadie, me bloqueé; me corté el cabello". Del mismo modo, refiere el S3: "Cargando culpa... no es vida esto, no es vida, es horrible, porque cada cosa cada sonido, cada olor, cada imagen, que me recuerda a lo que he vivido, no me deja escapar del pasado, de la verdad [...]". La $\mathrm{S} 4$, además advierte que ese estado lo viene cargando desde hace mucho "[...] antes tenía depresión y, yo decía me quiero morir y me quiero morir, y ya, yo decía pobrecita de mis hijas, cómo las voy a dejar solas, y le echamos ganas". Y precisa, que ese estado de depresión y angustia se le ha actualizado: "[...] pues problemas desde la niñez que tuve y que ahora, como ya me quedé sola, pues ya me están resultando". Así pues, en sus historias de vida hay una sumatoria de vivencias traumáticas que se expresan actualmente como una emergencia de emociones y de imágenes que no pueden controlar, en tanto que vienen de manera automática.

Además, esta afectación corporal sea de angustia o depresión ha llevado a algunas entrevistadas a tener ideaciones o actos de autodestrucción. La S2, refiere un relato en donde ante un conflicto con su madre no soportó más, sólo pensó en ella y su historia y decidió tomarse unas pastillas, cuenta que: "[...] y ya empecé a discutir con ella y todo, y ya me empezó a decir que yo no era bienvenida en su casa, y que estaba harta de tenerme ahí y todo, pues no pensé en nadie más que en mí; en lo que yo sentía, en todo lo que pasé cuando era niña, pues de que mi mamá, se tenía que ir a trabajar y yo quedarme ahí encerrada en la casa, entonces, me tomé las pastillas". La S3, advierte: "[...] quería, por ejemplo, inyectarme algo o quería tomarme algo, no sé, morir instantáneamente, ya no quería seguir viviendo, ya no: bien desesperante, nada más de repente acostada en el sofá, me empezaban las palpitaciones fuertes y salía, y salía a tomar aire y no podía respirar". Así mismo el S4, ante la pregunta del porqué del intento de acabar con su vida tomando pastillas, responde: "Yo digo que, por la depresión, ansiedad pues por lo que he vivido... Y porque cuando mis hijas se pelearon me eché la culpa”.

Actualmente emerge el sentimiento de culpa bajo tres vertientes, una al visualizar que la vivencia de abuso se repitió como es en el caso del S3, o por suponer que esas vivencias las llevaron a fracasar en su intento de ofrecer una familia a sus hijos o por los efectos negativos que actualmente padecen en sus recuerdos (S1, S2, S3 y S4). Se evidencia en los relatos de todos los entrevistados que siguen cargando con la vivencia de abuso como si hubiera sido culpa de ellas.

Finalmente, hay que decir que hay una metáfora que condensa de manera conclusiva sus historias. Estas son evidentes cuando narran que escuchan conceptos, voces que hablan sobre lo que es la vida, las cuales contrastan con sus propias vivencias. Como se ilustra a continuación: El S2, refiere: "Hay gente que por nada sufre [...] Yo sí he sufrido, no he tenido lugar, ni a nadie"; y el S3, sentencia: "[...] a veces pienso que no debí de haber nacido, ni yo, ni mi hijo [...] la gente dice que la vida es bella, esa gente está loca, la vida es dolor". La S4, expresa "[...] porque mi mamá nunca hablaba con nosotros, mi mamá siempre fue seria, como que para ella no existíamos". El S1, dice sobre las vivencias de violación: "[...] yo nunca pude decir nada a nadie. Me las guardé, entonces sí, sí le he batallado". Y termina sus relatos de padecimiento con una frase donde se auto alienta: "[...] pero siempre he salido adelante gracias a mi trabajo". 
Como se ve en el uso de estas metáforas, aparecen recurrentemente en los relatos adverbios de negación: nada, no, nunca, ni. En otros momentos los adverbios aparecen como un fracaso ante la intrusión por abuso. Por ejemplo, cuando el S1, fue violado la primera vez dice "yo no pude decir nada". Y cuando su padre se enteró porque lo estaban castigando al violador, "no dijo nada", y posterior al evento "nunca dijo nada". Es decir, el evento quedó sofocado y desestimado.

La S2, a propósito de que su padre se fue de su casa comenta: "[...] mi madre nunca dijo o dice nada de ello". Y cuando se fuga de la casa de la abuela refiere "me vine nada más por la calle". Y cuando se le pregunta sobre si sabía lo que el violador le estaba haciendo expone: "[...] pero ya no me importaba nada, ya no me importaba nada, por eso digo no puedo decir que me violó, porque total [...]". Algo similar cuenta cuando inició el trabajo sirviendo copas y charlando con los clientes en la cantina y el entrevistador inquiere: ¿cómo se sentía ahí?, a lo que responde: "[...] en el momento bien, era una adolescente, no me importaba nada". Y cuando se le reitera la pregunta, ¿cómo se vivía siendo tocada por extraños?, hace referencia a una escena nodal que permite entender la fuente de las desestimaciones de sí misma y del propio afecto, cuenta que: “[...] no sentía nada, cuántas veces no había pasado por muchas cosas hasta peores, ya eso no me importaba. Para mí lo peor es el maltrato de mi familia, que no me quisieran. Así que, qué más da que otra persona llegara y tocara mi cuerpo. No me importaba".

La S3, refiere sobre su niñez: "[...] prácticamente no tuve nada cuando era niña, con mi mamá, prácticamente nada digo... mí mamá no sabía cuidarnos". Cuando fue engañada por su marido hay unas escenas donde al preguntarle sobre ello responde: "él no decía nada", y ella se iba guardando todo, perdonaba. Pero cuando el marido tuvo un amorío con su sobrina entonces sí habló y sólo explotó cuando le contagio una enfermedad venérea. Cuando empezó a tener de pronto angustia y desánimo, le hicieron estudios y "no encontraban nada". Hasta que llegó una doctora y le dijo: "tiene una depresión profunda". La referencialidad a la nada y la soledad se actualiza cuando se enteró que su hijo se drogaba, expresa: "[...] sentí que estaba sola en el mundo, como perdida, ni a quién decirle, ni dónde sujetarme, como si todo hubiera desaparecido a mi alrededor, me sentía en el vacío".

Como se ve en este caso la negación emerge como ausencia de cosas básicas para dormir y de cuidados maternos. El marido frente a la confrontación de infidelidad hace desmentida de la realidad y ella sofoca el afecto, lo desestima hasta que explota. De frente a la búsqueda de causas corporales el médico le da una palabra para sostener sus síntomas: depresión profunda. Si bien, ella sabe que sufre por todo lo que ha vivido y no puede olvidar, como ilustramos párrafos arriba. Y de frente a la drogadicción de su hijo emerge de nuevo el no lugar en el mundo, el desamparo, el vacío. Se infiere que es porque en el acto de su hijo se repite toda su historia, la violación de ella y de su hijo, el hijo adicto como el padre y una madre incapaz de proteger. La vivencia de desamparo frente al violador adicto es ahora encarnada en su hijo. De frente a lo cual se culpa no sólo por lo que le hicieron al hijo sino por toda su historia. Queda entonces frustrada en su deseo de ofrecer una familia a sus hijos, de pronto parecería que no valió su esfuerzo.

La S4, refiere que después del abuso de su tío y del hombre al que le cuidaban la casa, no dijo nada ni ella ni su hermana, porque "mi mamá no hablaba con nosotros... como que para ella no existíamos". La desestimación del evento y de sus afectaciones aparece como nunca y como silenciamiento por ausencia comunicacional.

Como se ve en las narrativas la negación, el no lugar, es una constante en todos los casos. No hay una madre o un padre que cualifique la existencia del sujeto, sino al contrario, los tutores son quienes silencian, sofocan las vivencias traumáticas o quienes las ejecutan transgrediendo todo sentir humano. No hay un lugar físico para vivir, para resguardarse y no hay un lugar existencial para ser y proyectarse. Esta es la constante de todas las historias que tienen un final disfórico en tanto que no hubo un aparato simbólico que pudiera cualificar las vivencias traumáticas, por lo que en la actualidad no hay posibilidad de sofocar ni el recuerdo ni el afecto. Las narraciones están expuestas con la crudeza misma del vivenciar primero, y la falla en los procesos de simbolización o tramitación son 
revivencias, actualización de lo real en el cuerpo. La resiliencia tiene un límite, cuando hay una suma del padecer y una repetición de lo mismo, en tanto que los otros aparecen actuando la atrocidad o voluntad de crueldad y ellos como sujetos permanentes del despojo del no lugar.

Ante ese no lugar existencial agradecen ser atendidos en las clínicas, tener un lugar donde puedan escuchar sus síntomas corporales y su sufrimiento emocional. La institución y los profesionales ayudan a menguar su padecimiento, agradecen ser atendidos y que haya un lugar para ellos. Los profesionales psicólogos o psiquiatras aparecen aportando algo, escucha o medicamentos, aunque en el caso del S2, además el psiquiatra aparece ofreciéndole varios diagnósticos entre los que destaca un calificativo moral que condena su vida: "[...] otro diagnóstico, pues porque fui una prostituta, y he tenido muchísimos hombres en mi vida sexual, y para él, una mujer normal no tiene más de tres hombres en su vida". Esta escena es una descalificación que revictimiza a la paciente.

\section{DISCUSIÓN Y CONCLUSIONES}

A continuación, haremos un diálogo de los resultados antes expuestos con lo referido en la presentación del problema. Primero precisamos la consistencia de los resultados con los supuestos teóricos que sostienen cómo se da el fenómeno traumático, además de evidenciar los efectos. En un segundo momento se discutirá el carácter particular de los resultados, a saber: la desestimación del sujeto en tanto sujeto, dada la carencia de un lugar para vivir y un ambiente familiar donde existir.

Como se refería en la teoría siguiendo a Freud, el sujeto de frente a su imposibilidad de defenderse del agresor queda doblemente sometido en el silenciamiento del evento. Las defensas fracasadas que se infieren son la imposibilidad de sofocar el recuerdo y el afecto, la huida y la evitación. De tal modo que ante el fracaso de las defensas emerge en el acto la repetición de la vivencia traumática. Podemos inferir que al no ser tramitada la experiencia traumática y dada su reiteración del maltrato los sujetos quedan alienados al objeto hostil y actúan el maltrato en sí mismo con posterioridad exponiéndose a vínculos semejantes. Se coincide en este mecanismo de repetición con los estudios expuestos por Maker, Kemmelmeier \& Peterson, (2001, en Pereda, 2010).

Freud sostiene que los imperativos del superyó emergen como voces, por lo escuchado y vivenciado en el fenómeno traumático. Por lo que, posteriormente los recuerdos, imágenes, olores de lo vivido se liga preconscientemente con los juicios de rechazo y de desestimación padecidas por el sujeto, los cuales los expresa con sentimientos de culpa ${ }^{1}$. Si además de padecer en manos de otro la transgresión el sujeto signa la experiencia como siendo él la causa del evento, se instala un sentimiento de culpa inconsciente que empuja a realizar actos de autodestrucción, tomándose a sí mismo como objeto de la descarga del odio y violencia vivida. Dada la ausencia de un tercero que imparta justicia, que separe al agresor y al agredido para dar una sanción de discriminación del evento que "reparta culpas" o niveles de responsabilidad deviene un autocastigo. Toda vivencia traumática está acompañada por vergüenza de haber experimentado algo que no se pudo detener o prever. $\mathrm{Si}$ a ésta emergencia automática de vergüenza se le suman voces de parte de los agresores o de discursos sociales que culpan a la víctima, el sujeto queda entrampado en una revictimización dado que se silencia el evento y se autorecrimina. Coincidimos en esto con los resultados de Santana \& Machín (2005), quien define este fenómeno como una doble violencia por lo vivido y por el autosilenciamiento.

Los entrevistados S2, S3 y S4 expresan ideación e intentos suicidas, así como acciones autodestructivas. Se coincide en esto con otros estudios realizados por uno de los investigadores de este trabajo, Sánchez, Vázquez, De Santiago \& Penilla. (2017).

Los entrevistados S1, S3 y S4, dado que están al final de su vida como madres o padre, hacen un recuento de lo vivido y expresan frustración por sentir que su deseo de tener una familia fue inalcanzable.

1. Coincidiendo con los estudios de Yüce, Karabekirglu, Yildrim, Sahin, Sapmaz, Babadag, Turla, \& Aydin, 2015). 
Aquí podemos leer cierta caída del ideal de familia, pero además una doble frustración ya que la repetición no se pudo superar.

Los afectos emergentes en la vida adulta en sujetos que sufrieron abuso sexual infantil, son: depresión, pérdida de ánimo, ansiedad, pánico y estrés postraumático. Como se ve en la tabla 1 , todos los entrevistados expresan estos afectos displacenteros dadas las imágenes-recuerdos de las vivencias que devienen de manera automática. Así pues, quedan re-victimizadas, atrapadas en sus propios recuerdos. Coinciden estos resultados con los expuestos en otras investigaciones (Norman, Byambaa, De, Butchart, Scott, \& Vos, 2012; así como en Rani \& Kumar, 2016).

Las entrevistadas y el entrevistado vivieron el fenómeno del abuso con al menos uno de los siguientes agravantes: que el abuso fue por algún familiar y que después del mismo no había condiciones familiares que pudieran ir dando soporte para tramitarlo. Por lo que el sujeto queda en un estado permanente de indefensión, como refiere otro investigador: "el trauma es el resultado de un acontecimiento al que la persona no encuentra significado, y que experimenta como algo insuperable e insufrible" (Villanueva, 2013 p. 461).

Para abordar el uso del adverbio de negación peculiar en las narraciones analizadas, se apela a dos ideas, la primera es que el hombre a diferencia del animal no sólo necesita de un lugar para vivir sino de un sitio genealógico para existir. Y la segunda es, que sólo el humano tiene la capacidad de nihilizar el mundo y a sí mismo (Sarte, 2006).

Como se ha visto en el estado inicial de las narraciones (cuadro 1) a los entrevistados no se les ofrece un lugar dónde convivir familiarmente con otros. Al contrario, son abortados del mundo, de la solicitud humana positiva dada la nihlización de su ser en tanto existente por parte de los padres. El filósofo afirma:

Hay hombres guardianes, vigilantes, carceleros, etc., cuya realidad social es únicamente la del No, que vivirán y morirán sin haber sido jamás otra cosa que un No sobre la tierra. Otros, por llevar el No en su subjetividad misma se constituyen igualmente, en tanto que persona humana, en negación perpetua: el sentido y la función de lo que Scheler llama «el hombre de resentimiento» es el No. (Sartre, 2006, p. 43).

Por su parte afirma Heidegger, sólo la auténtica solidaridad -el compromiso en común- hace un sentido de las cosas que deje al otro en libertad de sí mismo. Las formas de estar en el mundo de los entrevistados las podemos situar bajo las coordenadas de la solicitud negativa, a saber: "[...] la falta de respeto y a la extrema indulgencia propia del indiferente" (Heidegger, 1993, p. 127). Los tutores los trataron con una indiferencia que como vimos está marcada por frases y actos de desestimación de sus afectos, de sus padecimientos y de transgresión a sus cuerpos; no les proporcionaron los cuidados a los cuales todo niño, todo humano tiene derecho.

Es creíble que muchas posiciones pasionales de pacientes que recurren al médico o al psicólogo son situaciones dramáticas por escenas imaginarias. No podemos decir que sea el caso de las escenas aquí analizadas, ya que los sujetos siguen luchando a pesar de las adversidades vividas. Narrativamente hablando, se pudo evidenciar que son colocados no como sujetos sino como abyectos, dado el abuso moral y sexual, por lo que entendemos que su padecer "neurótico" es por un real traumático (percepciones vividas y revivencias). Posicionalmente los sujetos fueron despojados de un lugar, de cuidados para existir positivamente en un mundo preñado de sentidos que potencie la proyección. Muy al contrario, el mundo concomitante a sus vivencias es gris, de desamparo y donde la degradación de la vida es lo único previsible, dada la sumatoria de atrocidades padecidas. Heidegger (1993) propone que comprender el mundo tiene una remisión que va haciendo que el sujeto infiere que se está en el mundo para algo, para lo cual toma eso que "está a la mano". En el mundo de las narrativas analizadas, se niega la solicitud positiva del existir humano. Lo que hay que decir con realismo es que todo humano tiene capacidad de dar de sí, cierta resiliencia, pero esta es contextual y como todo en el mundo tiene un límite. Cuando no sólo hay una vivencia traumática, sino que además hay fractura del mundo, de la cultura de la solicitud positiva para el cuidado, el sujeto no sólo está 
desorientado cognitivamente, sino que además queda expuesto su cuerpo el cual se abre sintomáticamente ahí, en eso que se es incapaz de simbolizar dada la crudeza de la atrocidad humana.

Concluyendo, como se ha escrito en otro momento, el otro como deinon (Sánchez, 2009) en un mundo carente de cuidados primarios hacen del padecer propio algo invivible, insoportable y que difícilmente se puede digerir, pues faltan palabras para exorcizar los actos padecidos. El mundo psíquico de los entrevistados, su desmoralización es la cultura que los acogió, los colocó como individuos de uso y desecho. La incapacidad de simbolizar la angustia automática que viven actualmente los entrevistados se puede considerar un reflejo de la cultura moderna que no acoge para cuidar sino, para anular el sentir humano.

\section{REFERENCIAS}

Adam, J. M. (1992). Los textos: tipos y prototipos. Relato, descripción, argumentación, explicación, diálogo. París: Nathan.

Amado, B., Arce, R., \& Herraiz, A. (2015). Psychological injury in victims of child sexual abuse: A meta-analytic review. Psychosocial Intervention, 24(1), 49-62. doi:10.1016/j. psi.2015.03.002

Aristóteles. (1999). La retórica. Madrid: Centro de Estudios Políticos y Constitucionales.

Banyard, V., Williams, L., \& Siegel, J. (2001). The Long-Term Mental Health Consequences of Child Sexual Abuse: An Exploratory Study of the Impact of Multiple Traumas in a Sample of Women. Journal of Traumatic Stress, 14(4), 697715 .

Barthes, R. (1970). Introducción al análisis estructural de los relatos. En R. Barthes, A. Greimas, C. Bremond, J. Gritti, V. Morin, C. Metz, . . . G. Genette, Análisis estructural del relato (págs. 9-44). Buenos Aires: Tiempo Contemporáneo.

Blanchet, A. (1987). Entrevistar. En, Técnicas de investigación en ciencias sociales. Madrid: Narcea.
Boyce, P., \& Harris, A. (2011). Childhood adversity, trauma and abuse: context and consequences. Australian and New Zealand Journal of Psychiatry (45), 608-610. doi:10.3109/00048674.2011.602209

Bremond, C. (1970). La lógica de los posibles narrativos. En R. Barthes, A. Greimas, C. Bremond, J. Gritti, V. Morin, C. Metz, G. Genette, Análisis estructural del relato (págs. 87-110). Buenos Aires: Tiempo Contemporáneo.

Cantón, D., \& Cortés, M. (2015). Consecuencias del abuso sexual infantil: una revisión de las variables intervinientes. Anales de psicología, 31(2), 552561.

Cantón, D., \& Justicia, F. (2008). Afrontamiento del abuso sexual infantil y ajuste psicológico a largo plazo. Psicothema, 20(4), 509-515.

Freud, S. (1984). El yo y el ello. En S. Freud, Obras completas (Vol. 19, p. 1). Buenos Aires: Amorrortu (Trabajo original publicado en 1923).

Freud, S. (1986a). El malestar en la cultura. En $S$. Freud, Obras Completas (Vol. 21, p. 57). Buenos Aires: Amorrortu (Trabajo original publicado en 1930).

Freud, S. (1986b). Esquema del psicoanálisis. En $S$. Freud, Obras completas (Vol. 23, p. 133). Buenos Aires: Amorrortu (Trabajo original publicado en 1940).

Freud, S. (1986c). Moisés y la religión monoteísta. En S. Freud, Obras completas (Vol. 23, p. 1). Buenos Aires: Amorrortu (Trabajo original publicado en 1939).

Freud, S., \& Breuer, J. (1985). Estudios sobre la histeria. En S. Freud, Obras completas (Vol. 2, p. 1). Buenos Aires: Amorrortu (Trabajo original publicado en 1893-95).

Greimas, A. (1970). Elementos para una teoría de la interpretación del relato mítico. En R. Barthes, A. Greimas, C. Bremond, J. Gritti, V. Morin, C. Metz, G. Genette, Análisis estructural del relato (págs. 45-86). Buenos Aires: Tiempo Contemporáneo.

Haileye, A. (2013). Psychopathological Correlates of Child Sexual Abuse: The Case of Female Students in Jimma Zone, South West Ethiopia. Ethiopian Journal of Health Sciences, 23(1), 32-38. 
Heidegger, M. (1993). El ser y el tiempo. Barcelona: Planeta-Agostini.

Lévi-Strauss, C. (1979). Introducción a la obra de Marcel Mauss. En M. Mauss, Sociología y antropología (págs. 13-44). Madrid: Tecnos.

Maldavsky, D. (2004). La investigación psicoanalítica del lenguaje. Buenos Aires, Argentina: Lugar.

Maldavsky, D. (2013). Algoritmo David Liberman. Buenos Aires: Paidós.

Malón, A. (2008). La hipótesis del trauma en el abuso sexual: revisión crítica e implicaciones. Revista Colombiana de Psicología (17), 177-200.

Nietzsche, F. (1997). La genealogía de la moral. Ciudad de México: Alianza.

Norman, R., Byambaa, M., De, R., Butchart, A., Scott, J., \& Vos, T. (2012). The Long-Term Health Consequences of Child Physical Abuse, Emotional Abuse, and Neglect: A Systematic Review and Meta-Analysis. PLoS Med, 9(11), 1-31. doi:10.1371/journal.pmed.1001349

Pereda, N. (2010). Consecuencias psicológicas a largo plazo del abuso sexual infantil. Papeles del Psicólogo, 31(2), 191-201.

Ramos, R. (2001). Narraciones contadas, narraciones vividas. Barcelona: Paidós Ibérica.

Rani, A., \& Kumar, M. (2016). Depression, anxiety, stress and suicidal ideas in adolescent victims of human trafficking and sexual abuse in a sheltered home at Ranchi, India. Indian Journal of Health and Wellbeing, 7(7), 687-690.

Rus, M., \& Buzarna, A. (2013). Psychological Aspects of Child Sexual Abuse. Contemporary Readings in Law and Social Justice, 5(2), 499-510.

Sánchez, A. (2009). Introducción al discurrir ético en psicoanálisis. Guadalajara: ITESO.

Fecha de recepción: 20 de mayo 2019

Fecha de aceptación: 30 de setiembre 2019
Sánchez, A., Vázquez, X., De Santiago, V., \& Penilla, O. (2017). Consistencias en las secuencias narrativas de los sujetos con intento suicida. En E. Camacho, V. De Santiago, B. Echeveste, J. García, C. González, L. Hernández, C. Vega,Investigación transdisciplinar del fenómeno suicida (págs. 141160). Ciudad de México: Manual Moderno.

Santana, L., \& Machín, R. (2005). El sufrimiento del adulto abusado sexualmente en la infancia. Una aproximación clínica. Revista Latinoamericana de Psicopatología Fundamental, 8(4), 679-693.

Sartre, J. P. (2006). El ser y la nada. Buenos Aires: Lozada.

Sigurdardottir, S., Halldorsdottir, S., \& Bender, S. (2012). Deep and almost unbearable suffering: consequences of childhood sexual abuse for men's health and well-being. Scadinavian Journal of Caring Sciences (26), 688-697. doi:10.1111/ j.1471-6712.2012.00981.x

Todorov, T. (1970). Las categorías del relato literario. En R. Barthes, A. Greimas, C. Bremond, J. Gritti, V.Morin, C.Metz, G. Genette, Análisis estructural del relato (págs. 155-192). Buenos Aires: Tiempo Contemporáneo.

Villanueva, I. (2013). El abuso sexual infantil. Perfil del abusador, la familia, el niño víctima y consecuencias psíquicas del abuso. Psicogente, $16(30), 451-470$.

Yüce, M., Karabekirglu, K., Yildrim, Z., Sahin, S., Sapmaz, D., Babadag, Z., . . . Aydin, B. (2015). The Psychiatric Consequences of Child and Adolescent Sexual Abuse. Nöro Psikiyatri Arsivi (52), 393-399. doi:10.5152/npa.2015.7472 